\section{Always look on the bright side: LIS research since 2000}

\author{
Peter Brophy
}

\begin{abstract}
Author
Professor Peter Brophy is Director of the Centre for Research in Library \& Information Management (CERLIM) at Manchester Metropolitan University. Between 1989 and 1998 he was Head of Library and Learning Resource Services at the University of Central Lancashire, where CERLIM was founded in 1993. A former President of the Institute of Information Scientists, he has led a variety of large research projects and has published widely in the field - most recently Measuring Library Performance (Facet, 2006).
\end{abstract}
Abstract
This paper outlines the library and information science (LIS) research environment which has developed over the last six years, focusing on the key research funders and the research themes which have emerged. It suggests that, while there is significant funding available for research, the funding environment is challenging and highly competitive. It is argued that, in general, LIS research, including that undertaken by and with practitioners, needs to develop a firmer theoretical and contextual foundation and that there is a need to distinguish between supporting studies, often with an implicit or explicit advocacy agenda, and research.

\section{Introduction}

Other contributors to this special issue have already acknowledged the debt of gratitude which all involved in library and information science (LIS) research owe to Brian Perry. My own experience echoes this. My very first appointment, immediately after graduating, was as a Research Associate working on a project at Lancaster University's Library Research Unit (LRU), funded by the Office for Scientific \& Technical Information (OSTI), soon to become the British Library Research \& Development Department (BLRDD). It is a measure of Brian's willingness to experiment and take risks that, back in 1970, OSTI funded research into computer simulation of library services. This was in the days when each university had only one computer, and response times were measured in hours or days rather than seconds! The enduring effects of Brian's imaginative support is exemplified in the careers of those involved at Lancaster, including Michael Buckland, later to become Dean of the library school at the University of California, Berkeley, and Geoffrey Ford, who retired as University Librarian at the University of Bristol only a short time ago. Thus the effects of research funding extended well beyond the projects themselves.

My topic is LIS research since 2000, following on from Derek Law's paper, and I will try to cover this very large topic mainly by looking at the activities of the key funding bodies in the field during that period. First, however, it is worth examining the issue from the other end of the telescope, by looking briefly at what the departments of library and information science (or whatever title each currently goes by) declare as their research funding sources. Table 1 below is derived from an examination of the departments' websites carried out in early November 2006: where a department is omitted this is because it proved difficult to identify the required data from the website and does not necessarily mean that the department has not received external research funding. Having said that, it is becoming clear that the number of UK departments with significant research activity is probably approaching single figures and certainly much lower than it has been in the past. 


\begin{tabular}{|l|l|}
\hline University & Declared funding sources on website \\
\hline Brighton & AHRC, EU-IST, MLA \\
\hline City & EPSRC, ESRC, EU-IST, Microsoft Research \\
\hline Loughborough & AHRC, ESRC, JISC, EU-IST, NHS \\
\hline MMU & ESRC, EU-IST, JISC, MLA \\
\hline Robert Gordon's & ESRC, EU-ALFA, MLA \\
\hline Sheffield & $\begin{array}{l}\text { AHRC, BBSRC, EU-IST, JISC, MLA, various } \\
\text { chemicals/pharmaceuticals companies }\end{array}$ \\
\hline Strathclyde & EPSRC, EU-IST, JISC, various regional organisations \\
\hline UCL & AHRC, DoH, NHS, various publishers \\
\hline
\end{tabular}

Table 1: Research funding sources

As will be apparent, the research active departments are drawing funding from a similar mix of sources, though with some particularities related to the well-known strengths of the individual departments. Thus Sheffield's long association with information services in the chemicals and pharmaceuticals industries is reflected in funding from those sources, while Dave Nicholas' work with publishers at University College London is similarly reflected in funding.

By and large however, the departments have been in receipt of funding from the UK Research Councils, the European Commission's Framework Programmes, the Joint Information Systems Committee (JISC) and the Museums, Libraries and Archives Council (MLA), together with the specialist sources identified above. I will discuss each of these as research funders later.

However, before doing so it is important to recognize that there is also a strong strand of practitioner research, much of it funded by libraries or library consortia. It is therefore useful to begin by looking at that tradition.

\section{Internal funding}

Undertaking research within the context of practice and by practitioners has a long history and indeed was supported by OSTI and its successors. Looking at this strand of activity today, it is apparent that the major source of funding being utilised is internal rather than from external agencies, with considerable evidence of collaboration between libraries in such areas as the assessment of quality (LibQUAL+ ${ }^{\mathrm{TM}}$ being the best example), information literacy and evidence-based practice (EBP).

However, a close examination of what is happening in such areas leads to the conclusion that the research base for many of these initiatives is rather weak. The LibQUAL+TM work (see www.libqual.org), to take that example, was undertaken initially in the USA under the auspices of the Association of Research Libraries and builds on the SERVQUAL methodology (Parasuraman et al., 1988). From a research perspective, however, the widespread implementation of the library version raises a number of questions which would form a useful and, given the widespread adoption of the approach, important research agenda. For example, how valid is a methodology based on expressed user expectations and more broadly on the mantra that the customer is always the best judge of quality? - a question increasingly raised in the broader service sector. Or again, what is the relevance to the total student experience, and to student achievement, of the library as place?

A similar library-centric view seems to have gripped the information literacy movement. Even after years of endeavour, it is rare to find anyone other than librarians using the term. What more broadly-based commentators and researchers do discuss is the more general issue of literacies, including such concepts as 'situated literacies', the relationships between 
literacies and learning and teaching methods and the pedagogical basis of those methods. Yet at a time when the prevailing pedagogical approach has swung so firmly towards constructivism, we find much delivery of information literacy programmes determinedly objectivist in outlook. The field abounds with research questions, but are they being addressed?

There is a sense in which the adoption of EBP is a shift towards a research-based practitioner culture. However, we need to distinguish between the identification of evidence to be used in decision making and the conduct of primary research. Further we need to be sure that the research paradigms underpinning EBP are appropriate to the intended environment. In some ways it is unfortunate that EBP has emerged from the health sector, where the emphasis is on randomised controlled trials (RCT). This pushes EBP proponents towards a positivist stance which is at odds with much work on social systems (of which libraries are surely an example). I have written elsewhere:

the positivist approach has an irreconcilable difficulty when applied to real-world social systems, namely that it is literally impossible to control all the variables. A scientific experiment relies on the ability of the researcher to carry out the experiment within a closed system, or as close to that as is possible to achieve. Thus medical researchers go to enormous lengths to minimise any bias introduced by external factors - even in the laboratory this is a major issue. But social systems, which include libraries, do not and cannot operate in such conditions.

(Brophy, 2007).

The research challenge behind EBP, therefore, is not to carry out more and more largely quantitative studies of library services but to explore new investigative approaches - new methodologies for gathering and evaluating evidence - within a post-positivist paradigm which is open to, inter alia, critical approaches.

The above examples perhaps illustrate the difficulty of defining research in the context of practice. To some, the application of a methodology such as LibQUAL $+{ }^{\mathrm{TM}}$ will itself count as 'research' - it is exploring the local environment and the library's place within it. However, to the academic research community this would not so qualify: there needs to be a real research question, answering which would advance knowledge, and significant generalisability of the results. There would also be some development of research methodologies, and not just evaluative tools.

\section{The Joint Information Systems Committee (JISC)}

There is no doubt that the funding which JISC has delivered through its development programmes has been significant, and continues to be so. The nature of its remit means that this funding is associated with the development of information and communications technology (ICT) services of benefit to the academic sector, but the remit has been interpreted widely and in any case libraries are now inextricably part of the global ICT-based information environment. The availability of JISC funding, especially through the Distributed National Electronic Resource (DNER) and Information Environment (IE) Programmes and more recently through eLearning and eResearch funding, goes a long way to explain the dominance of the academic sector in terms of leading edge developments among UK libraries. The agenda has featured a wide variety of concerns, including but not limited to:

- Information architectures

- Solutions to the appropriate copy problem (through resolver and associated developments)

- Repositories

- eLearning systems and processes, including virtual learning environments (VLEs)

- Support for researchers, including exploitation of the Grid and development of Virtual Research Environments (VREs).

While much of JISC-supported work has been developmental in nature there has been a strong strand of research running through all the programmes. In addition the JISC has provided support for a number of centres which have a significant research track record associated with 
their core work - UKOLN, the Centre for Educational Technology \& Interoperability Standards (CETIS) and the Digital Curation Centre (DCC) would be good examples. The last, for example, receives considerable funding from the research councils for work which meets the highest standards of academic, peerreviewed research.

\section{Corporate funders}

It is difficult to generalise about the contribution of research funders from the corporate sector. Certainly LIS researchers have scored notable successes in attracting such funding, especially in niche areas (some of which were mentioned earlier) and there have been individuals whose research has seen significant support from major corporations - Stephen Robertson's work at Microsoft Research in Cambridge is an excellent example.

In this context it is also worth mentioning research foundations and similar bodies. In general these have not been very prominent as funders in our field, although it is worth mentioning the likes of the Eduserv Foundation and the work of OCLC - whose founder, Fred Kilgour, also died in 2006.

\section{The Museums, Libraries and Archives Council (MLA)}

As Derek Law has pointed out the responsibility for LIS research funding passed from the British Library to the Library \& Information Commission (LIC), which had an explicit role in funding research programmes. However, while the MLA honoured commitments to funded projects which the LIC had made, there has been no programme of funded research as such. Academic departments and libraries have been able to bid to the MLA for a variety of studies, although in practice most of these have been more of the nature of consultancies than academic research projects. This change perhaps highlights again the critical issue of what we mean by 'research' when we talk of 'the LIS research agenda'. The widest definition would no doubt include market research, a wide variety of consultancies and a plethora of studies based on individual library and information services. But that is not what Brian Perry and the BLRDD set out to achieve all those years ago, and nor is it - at least in the opinion of this author - adequate to secure the health of a profession facing a multitude of challenges and competitors.

The MLA has tried to position itself as the spokesperson for the whole of the library (and museum and archive) sector, but this has met variable success in practice. If the academic sector is the most dynamic in terms of $\mathrm{R} \& \mathrm{D}$, as I have argued above, it is also the least engaged with the MLA - partly because its funding comes from the Department for Education \& Skills rather than the MLA's parent Department for Culture, Media and Sport (DCMS). It is disappointing that an initiative which might have rectified this situation, the Common Information Environment (CIE), failed to make much progress - particularly as the achievement of interoperable infrastructures would facilitate collaborative service provision across sectors. The replacement of the CIE with a 'Strategic eContent Alliance' (see http://www.jisc.ac.uk/ whatwedo/themes/eresources/sea.aspx) led by the JISC is a recent development, but this appears to shift the focus onto guidelines and 'good practice' rather than research and development into the enabling environment which is most critical to future progress and most in need of researchers' attention.

Recently the MLA has espoused a regional approach, directing resources to the regional agencies within the MLA Partnership. Again, what is seen emerging in the regions is a pattern of studies which are supportive of a variety of initiatives, often with an emphasis on advocacy, but hardly 'research' in the sense discussed above. The exception is Scotland where the closeness of the sector to the Scottish Executive and the active involvement of the Scottish Library \& Information Council (SLIC) seems to have enabled a number of research-based studies to be undertaken.

It would be wrong to criticise MLA unduly for this situation. It has a policy, prominently 
displayed on its website, of "directing more resources to frontline services" while operationally its four divisions are Policy \& Advocacy, Operations, Marketing \& Communications and Corporate Services. The development of knowledge per se is not within its remit, which brings us to the Research Councils.

\section{Research Councils}

The primary focus for LIS research funding lies with the Arts \& Humanities Research Council (AHRC), although it is clear from the brief analysis of LIS Departments' funding sources reported earlier that many are securing support from other Councils, including the Economic and Social Research Council (ESRC), the Engineering and Physical Sciences Research Council (EPSRC) and even the Biotechnology and Biological Sciences Research Council (BBSRC). This situation exemplifies one of the problems for our sector: information research is by its nature cross-disciplinary, but draws heavily on both technological development (hence EPSRC) and understanding of human social systems (hence ESRC). Sometimes it is specialised in relation to particular disciplines (hence BBSRC and others). While it is good that LIS has a recognised 'home' within the AHRC the downside can be an assumption that the fit of the whole discipline is best expressed through association with the arts and humanities.

Whatever the effects may be, it is important to recognise that Research Council funding is largely distributed through what are called 'responsive mode' schemes. In other words the ideas for research are generated by the researchers themselves, who then apply for funding in competition with others. While there are important targeted programmes these are not the primary modus operandi of the Councils, and certainly not of the AHRC. Proposals are assessed by peer review and then by an expert panel, with the main criterion being the excellence of the research as research, rather than relevance to practice or applicability.

Within this system, LIS has not been very successful. As a member of the relevant Panel for the last three years, and Convenor of the Postgraduate Panel, I have seen at first hand the shortcomings of the proposals we received. As I reported to a meeting of the British Association for Information \& Library Education \& Research (BAILER) last year, the main weaknesses relate to inadequate attention to the theoretical basis of the proposed research and insufficient consideration of methodologies.

While the AHRC does operate some targeted programmes, it was unfortunate that in 2005, when decisions were made on priority areas, proposals from the LIS panel were unsuccessful.

One difficulty we have to face is that it can sometimes appear as if LIS is receiving considerable funding from AHRC. However, these sums relate mainly to support for libraries to develop access to collections, often through digitisation rather than research and to the support of university museums.

\section{The European Union}

Very considerable support to LIS research has been provided through the European Commission's Framework Programmes. Despite the disappearance of a discrete 'Libraries Programme', many areas of critical concern have been included in more broadlyframed approaches within what is now known as the Information Society Technologies (IST) Programme. The work programme for Digital Libraries and Technology-enhanced Learning under the Framework 7 Programme has recently been announced, and includes seven 'challenges', one of which relates to Digital Libraries and Content. Posing the question, 'Where do we want to go?' the Programme suggests we need research into:

Digital library services, anchored in the digital content infrastructure, enabling us to create, store, personalise and use over time cultural and scientific content.

The ability to access, use and understand today's digital information in the future, through systems and tools for digital preservation. 
Always look on the bright side

Peter Brophy

Creation and management of intelligent content needs to be more effective. We must be able to manage the workflow from the acquisition of reference materials to the versioning, packaging and repurposing of products, as well as its distribution, presentation and consumption.

New learning environments that are responsive, personalised and intuitively adapt to the learner's and teacher's needs and that can motivate, engage and support development of skills and competences.

(http://cordis.europa.eu/fp7/ict/programme/over view4_en.html)

These are clearly major challenges, and set an exciting agenda. It should also be recognised that other parts of the Framework Programme, and certainly other strands of IST, are hospitable to LIS-related research - my own Centre (CERLIM) is heavily involved in the eInclusion Programme, for example, which is supporting research in the area of accessibility of digital content, liaising closely with the World Wide Web Consortium's Web Accessibility Initiative (W3C/WAI).

Having said that, it has to be acknowledged that securing research funding from the European Commission is extremely challenging.

Although there is some practitioner involvement, projects tend to be ahead of practice (for example, we were investigating RFID technologies ten years before they became viable products in the library marketplace). On the other hand, this enables researchers to explore new paradigms of service and to do so in an environment which is highly hospitable to exploitation of findings in practice.

\section{Conclusions}

In drawing conclusions I would like to return to one issue which runs through the various funded research in our sector, namely the methods (or if you prefer, methodologies) which we use.

Given that the research councils are the source of funding for the most advanced research, it is worrying that it is this area that we appear to be relatively weak. That we will continue to borrow widely from other disciplines is not in doubt, nor should it be a source of concern.
Library \& Information Research (LIR)

Volume 31 - Number 97 - Special Edition 2007

However, we perhaps need to spend more time, and find ways to encourage younger researchers in particular, in understanding the theoretical foundations upon which methods are based. Because ICTs play such a large part in LIS these days, many methods are more concerned with systems development than research, and this may have weakened our research base. More positively, there is now a much wider acceptance of social science methods, including qualitative approaches, even if the proponents of EBP have been slow to recognise this.

My overall conclusion, however, is that there remains a large amount of funding available to LIS researchers. However, the environment in 2006 is undoubtedly far more competitive than it was even six years ago and certainly at BLRDD's foundation in 1974. Researchers need to present well thought out proposals which demonstrate a clearly articulated research question, sound methodologies, innovative ideas and a clear understanding of the theoretical basis of their proposed research. They need to be persistent, with a long-term view. They need to work in partnership with others who can bring varied skills to the table. We should certainly not be gloomy - the opportunities are there for a new generation of researchers to build on the legacy that Brian Perry and so many others down the decades have helped to create. I hope this workshop will prove to have been a significant milestone on the road to that future.

\section{References}

Brophy, P. (2007) Narrative-based practice. Evidence Based Library and Information Practice, 2(I) (In the press.)

Parasuraman, A., et al. (1988) SERVQUAL:A multipleitem scale for measuring customer perceptions of service quality. Journal of Retailing 64(I), 12-40. 